\title{
Evaluación del potencial energético de residuos de cacao ( Theobroma cacao L.) por medio de celdas de combustible microbiano (CCM)
}

\author{
Claudia C. Plasencia-Verde ${ }^{1}$, Katherine S. Grabiel-Rios ${ }^{1}$, José A. Luque ${ }^{2}$ e Ivan K. Best ${ }^{1,3 *}$ \\ (1) Facultad de Ciencias Ambientales, Carrera Ingeniería Ambiental, Universidad Científica del Sur, Lima, Perú. \\ (correo-e: 100010179@ucientifica.edu.pe; kgrabriel@cientifica.edu.pe) \\ (2) Facultad de Ciencias Empresariales, Dirección Académica de Cursos Básicos, Universidad Científica del Sur, Lima, \\ Perú. (correo-e: jluque@cientifica.edu.pe) \\ (3) Unidad de Investigación en Nutrición, Salud, Alimentos Funcionales y Nutracéuticos, Universidad San Ignacio de \\ Loyola (UNUSAN-USIL), Lima, Perú. (correo-e: ibest@usil.edu.pe)
}

${ }^{*}$ Autor a quien debe ser dirigida la correspondencia

Recibido Dic. 11, 2020; Aceptado Feb. 8, 2021; Versión final Abr. 8, 2021, Publicado Ago. 2021

\begin{abstract}
Resumen
El objetivo de esta investigación fue evaluar el potencial energético de los residuos de cacao (mazorca y mucílago) como fuente de energía directa en campo. Se realizaron tres diluciones por sustrato. Mazorca triturada $(<0.5 \mathrm{~mm})$ en diluciones de 1:25 $(1.20 \mathrm{~g}), 1: 50(0.60 \mathrm{~g})$ y 1:100 $(0.30 \mathrm{~g})$ y mucílago en diluciones de $1: 4(25 \%), 1: 8(12.50 \%)$ y $1: 16(6.25 \%)$. La evaluación fue realizada en celdas de combustible microbiano en tres períodos: aclimatación (un período) y desempeño eléctrico (dos períodos). Durante el tercer período, se observó el mayor desempeño eléctrico en las diluciones de mazorca $1.20 \mathrm{~g}$ (voltaje: $726 \mathrm{mV}$; densidad de potencia: $11.75 \mathrm{~mW} / \mathrm{m} 2$; eficiencia coulombica: $0.33 \%$ ) y mucílago $12.50 \%$ (voltaje: $474 \mathrm{mV}$; densidad de potencia: $6.52 \mathrm{~mW} / \mathrm{m} 2$; eficiencia coulombica: $0.01 \%$ ). Se concluye que las diluciones de mazorca (1.20 g) y mucílago (12.50\%) presentaron el mayor potencial energético a lo largo del estudio.
\end{abstract}

Palabras clave: potencial energético; celda de combustible microbiano; cacao; residuos orgánicos; microorganismos

\section{Evaluation of the energy potential of cocoa (Theobroma cacao L.) residues by microbial fuel cells (MFC)}

\begin{abstract}
The main objective of this research study was to assess the energy potential of cocoa residues (pod and mucilage) as a direct energy source. Three dilutions were made per substrate. Crushed pod $(<0.5 \mathrm{~mm})$ diluted in 1:25 (1.20 g), 1:50 (0.60 g), and 1:100 (0.30 g). Mucilage diluted in 1:4 (25\%), 1:8 (12.50\%), and 1:16 (6.25\%). Measurements were performed in microbial fuel cells in three periods: acclimatization (one period) and electrical performance (two periods). During the third period, the highest electrical performance was observed in the $1.20 \mathrm{~g}$ pod dilution (voltage: $726 \mathrm{mV}$; power density: $11.75 \mathrm{~mW} / \mathrm{m} 2$; coulombic efficiency: $0.33 \%$ ) and in the $12.50 \%$ mucilage dilution (voltage: $474 \mathrm{mV}$; density power: $6.52 \mathrm{~mW} / \mathrm{m} 2$; coulombic efficiency: $0.01 \%)$. It is concluded that the dilutions of pod $(1.20 \mathrm{~g})$ and mucilage $(12.50 \%)$ showed the highest energy potential.
\end{abstract}

Keywords: energetic potential; micro fuel cell; cocoa; organic waste; microorganisms 


\section{INTRODUCCIÓN}

El Perú es el décimo exportador de semillas de cacao, representando un $1.50 \%$ de las exportaciones a nivel mundial (Internacional Trade Centre, 2020). En el Perú, en el año 2018, el rendimiento anual fue de $827 \mathrm{~kg} / \mathrm{ha}$, con una producción de 134,676 toneladas. Esta cadena productiva representa una fuente importante de ingresos para los cacaoteros peruanos, el 95\% del mercado peruano está representado por pequeños productores familiares (Romero, 2016; Ministerio de Agricultura, 2020). No obstante, existe una alta desorganización, lo cual genera ineficiencias en la cadena productiva, lo que conlleva a una inadecuada gestión de los residuos de cacao, y provoca contaminación de suelos y agua (Morales et al., 2015).

En la cadena productiva del cacao, el $70 \%$ es representado por los residuos sólidos y líquidos, entre los cuales se encuentra el mucílago, mazorca, lixiviados de la fermentación e impurezas (Botero et al., 2016). El mucílago de cacao se genera en una proporción de $1 / 20(\mathrm{~V} / \mathrm{m})$, respecto a la producción de granos de cacao (Arteaga, 2013). Este residuo es viscoso debido al contenido de pectina y otros polisacáridos en su composición, lo que dificulta el paso del aire a través del medio, promoviendo así un ambiente anaerobio. Por otro lado, la mazorca de cacao se desecha 10 veces más respecto al peso en producción de semillas secas de cacao. El vertimiento de subproductos del beneficio del cacao al suelo produce una variación en las propiedades químicas del mismo, aumenta la humedad y riesgo de enfermedades infecciosas (Campos-Vega et al., 2018).

Las celdas de combustible microbiano (CCM) representan una tecnología novedosa, generadora de energía, la cual aprovecha la capacidad catalizadora de los microorganismos sobre la materia orgánica. Se han realizado diferentes investigaciones sobre su funcionamiento utilizando como sustrato aguas residuales (Chaturvedi y Verma, 2016), diferentes concentraciones de azúcares (Christwardana et al., 2018) y evaluación del rendimiento microbiano (Patil et al., 2009). Entre los tipos de CCM, se encuentra aquella que posee solo la cámara anódica (donde se encuentra el ánodo), mientras el cátodo se encuentra expuesto al aire, obteniendo un mayor potencial de generación eléctrica (Velarde et al., 2017).

Con el fin de atenuar los efectos adversos del mucílago y mazorca de cacao en los campos de cultivo, en el presente estudio se evaluó su desempeño energético mediante CCM de una sola cámara. Esta tecnología fue escogida por su versatilidad, capacidad de funcionamiento con distintos productos naturales, obtención de energía de manera directa, y facilidad de uso en lugares carentes de infraestructura eléctrica (Mora y Bravo, 2017). El objetivo del presente estudio fue evaluar el potencial energético de los residuos líquidos y sólidos de cacao (Theobroma cacao L.), tales como el mucílago y mazorca, para la obtención de energía eléctrica en un modelo basado en CCM.

\section{MATERIALES Y MÉTODOS}

La metodología utilizada para la presente investigación se describe ne las siguientes cinco subsecciones: electrodos y construcción de la celda de combustible, tratamientos, aclimatación de los microorganismos, experimento, desempeño eléctrico, y análisis de datos

\section{Electrodos y construcción de la celda de combustible}

En la Fig. 1, se muestra la celda de combustible microbiana de una sola cámara utilizada en el estudio, habiendo utilizado como base la configuración presentada por Martinez et al., 2017. Se elaboró una cámara acrílica cilíndrica de $4 \mathrm{~cm}$ de longitud por $3 \mathrm{~cm}$ de diámetro, equivalente a un volumen de $28 \mathrm{~mL}$. En un extremo de la celda, se colocó el ánodo de papel carbón Toray 060 con un $5 \%$ en peso de material a prueba de agua, el cual fue cubierto con una tapa del mismo material de la celda para no permitir el ingreso de oxígeno. Al otro extremo, se colocó el cátodo de fibra de carbono con un contenido de $0.30 \mathrm{mg} / \mathrm{cm}^{2}$ de $40 \%$ de platino en carbón Vulcan, y se sujetó a la celda con una tapa que permitía el contacto del cátodo con el aire. Para la unión del circuito, se utilizó alambre de platino de $0.50 \mathrm{~mm}$ (Unitech, USA).

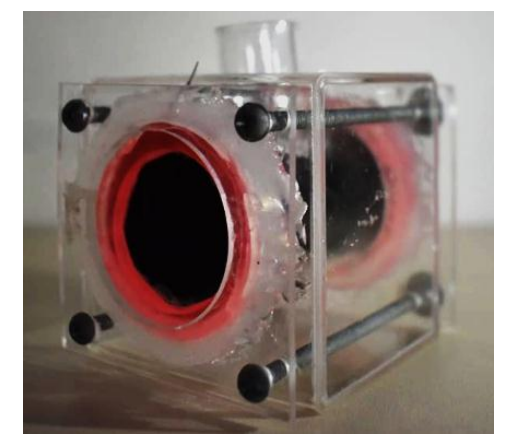

Fig. 1: Configuración de celda de combustible microbiano (CCM) utilizada en el presente estudio. 


\section{Tratamientos}

Con el fin de determinar la influencia de la concentración de mucílago y mazorca de cacao (Theobroma cacao L.) en la producción de energía, se utilizó el cacao CCN-51 procedente del Distrito de Cajaruro, Provincia de Utcubamba, Región Amazonas, Perú. La mazorca fue secada en una estufa a $40^{\circ} \mathrm{C}$ por 7 días y luego sometida a molienda hasta alcanzar un diámetro menor a $0.5 \mathrm{~mm}$. Se evaluaron tres tratamientos y un control negativo de agua destilada. En el caso del mucílago, se trabajó con proporciones de 1:4 (mucílago 25\%), 1:8 (mucílago $12.50 \%$ ) y $1: 16$ (mucílago $6.25 \%$ ), diluido en agua destilada; mientras que, para la mazorca, se evaluaron las proporciones de 1:25 (mazorca $1.20 \mathrm{~g}$ ), 1:50 (mazorca $0.60 \mathrm{~g}$ ) y 1:100 (mazorca $0.30 \mathrm{~g}$ ), diluido en agua destilada.

\section{Aclimatación de los microorganismos}

La muestra ambiental utilizada para la investigación fue tomada de los sedimentos del río Lurín, Región Lima, Perú (Coordenadas UTM WGS84 Zona 18S - 293785.7E, 8643547.7N), durante la época seca (mayonoviembre), aproximadamente a $200 \mathrm{~m}$ de la tubería de descarga del proyecto Mesías (aguas residuales). Se extrajo $500 \mathrm{~mL}$ de sedimento, del cual se tomó $1 \mathrm{~mL}$ y se añadió a $50 \mathrm{~mL}$ de muestra, de acuerdo a las diluciones descritas en los tratamientos. Dicho período tuvo una duración de dos semanas, en las cuales se controló temperatura y $\mathrm{pH}\left(25^{\circ} \mathrm{C}\right.$ y 6.50 , respectivamente). Finalizado dicho período, se procedió a realizar el sembrado del consorcio en agar Brewer ( $\mathrm{pH}$ 7.20). Al término de la incubación (10 días, $30^{\circ} \mathrm{C}$ ) se inoculó el consorcio en medio de Tioglicolato y se conservó a $4{ }^{\circ} \mathrm{C}$ hasta su utilización en el experimento. Durante las

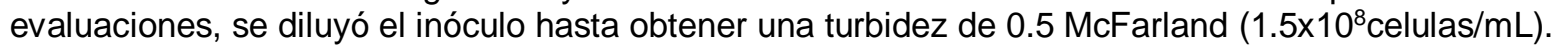

\section{Experimento}

Para la evaluación del desempeño eléctrico, se agregó $0.50 \mathrm{~mL}$ del inóculo $(0.5 \mathrm{McF}$ arland $)$ a $29.50 \mathrm{~mL}$ de las diferentes diluciones de mucílago y mazorca, y se colocó en las CCM. Desde el inicio del experimento, se controló el $\mathrm{pH}$ inicial (papel tornasol Panpeha-Whatman) y temperatura $\left({ }^{\circ} \mathrm{C}\right)$, y se registró el voltaje $(2000 \mathrm{mV})$ y amperaje $(2000 \mu \mathrm{A})$ utilizándose un multímetro digital (Truper). El pH y la temperatura se mantuvieron en un rango de 5.50 a 7.00 y 25 a $26^{\circ} \mathrm{C}$, respectivamente. La experimentación se dividió en tres períodos de 7 días cada uno. Se realizó mediciones horarias de voltaje y amperaje en el horario de 9:00 a 21:00, y del total de datos obtenidos, se utilizaron 76 datos por parámetro para el análisis del desempeño eléctrico. El primer período consistió en la población y fijación de los microorganismos (aclimatación) en el ánodo (Kong et al., 2018), mientras que en los dos siguientes se evaluó el desempeño eléctrico. La demanda química de oxígeno (DQO) se analizó al inicio y al final del período, de acuerdo al método estandarizado SMEWW-APHA-AWWAWEF Parte 5220 D (APHA et al., 2017).

\section{Desempeño eléctrico}

Para el análisis del desempeño eléctrico de las cámaras se midió el voltaje (U) y la intensidad de corriente (I), a partir de los cuales se obtuvo la potencia (W), densidad de potencia por unidad de área del electrodo anódico (A) $\left(\mathrm{mW} / \mathrm{m}^{2}\right)(1)$, densidad potencia por unidad de volumen del sustrato $(\mathrm{V})\left(\mathrm{mW} / \mathrm{m}^{3}\right)(2)$ (Chouler et al., 2016) y eficiencia coulómbica $\left(\mathrm{C}_{\mathrm{p}} / \mathrm{C}_{\mathrm{ti}} 100 \%\right)$, donde $\mathrm{C}_{\mathrm{p}}$ es el total de Coulomb, calculados a partir de la integración de la corriente en el tiempo y $\mathrm{C}_{\mathrm{ti}}$ es la cantidad teórica de Coulomb que se produce a partir del sustrato (3) (Liu y Logan, 2004).

$$
\begin{aligned}
& P_{A}=\frac{I * U}{A} \\
& P_{V}=\frac{I * U}{V} \\
& \mathrm{C}_{\mathrm{ti}}=\frac{\mathrm{FbS}_{\mathrm{i}} \mathrm{V}}{\mathrm{M}_{\mathrm{i}}}
\end{aligned}
$$

\section{Análisis de datos}

Se utilizó el error instrumental definido como \pm ( $a \%$ de la lectura $+b$ dígitos), siendo en este caso $a=0.5$ y b=2. No se utilizó el error de método de medición debido a la influencia de la degradación microbiológica del sustrato a través del tiempo. 


\section{RESULTADOS Y DISCUSIÓN}

Los resultados se encuentran descritos en función al sustrato utilizado; primero se muestran y discuten los resultados para los experimentos con (mazorca y luego se hace lo mismo para los resultados con mucílago.

\section{Mazorca}

Se utilizaron muestras con 377,425 y $581 \mathrm{mg} \mathrm{O} / \mathrm{L}$ de $\mathrm{DQO}$, correspondiente a las diluciones de mazorca de $1.20,0.60$ y $0.30 \mathrm{~g}$, respectivamente. Cuando dichas muestras fueron introducidas a las CCM, presentaron voltajes iniciales de $60 \pm 2.30 \mathrm{mV}, 140 \pm 2.70$ y $120 \pm 2.60$, respectivamente (Figura 2); siendo la muestra de mazorca $1.20 \mathrm{~g}$, la que presentó un menor voltaje al iniciar el estudio. Lu et al., (2009) registró un voltaje inicial de $87.90 \mathrm{mV}$, en dicho estudio se utilizó un circuito el cual consistía en agregar muestra $(425 \mathrm{~mL})$ cuando el voltaje se encontraba a $0.5 \mathrm{~V}$, además de utilizarse una membrana de intercambio de protones. Logroño et al., (2015) presentó valores iniciales de 41,50 y $38 \mathrm{mV}$ para una celda anódica de $4 \mathrm{~L}$ de materia orgánica y suelo amazónico. Dichos resultados fueron similares a nuestro estudio, y en algunos casos el voltaje inicial de las muestras evaluadas fue mayor a los valores registrados por estudios anteriores (Lu et al., 2009; Logroño et al., 2015). Como se muestra en la Figura 2, las diluciones de mazorca presentaron voltajes entre -340 y $585 \mathrm{mV}$. Los menores valores de voltaje se presentaron en el segundo período para las diluciones de mazorca 1.20 y $0.30 \mathrm{~g}$. La primera, presentó un valor mínimo al inicio de este período, mientras que la segunda registró valores negativos las tres primeras horas del segundo período.

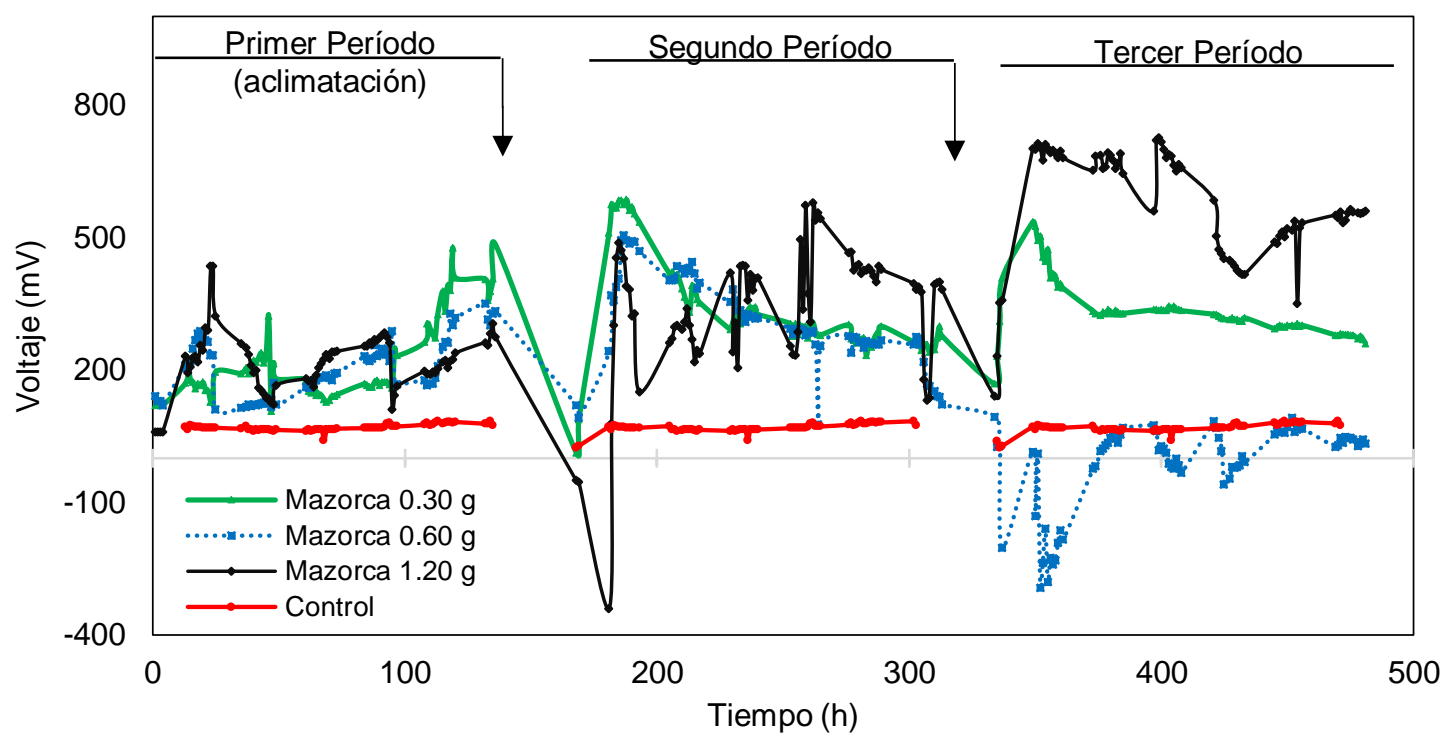

Fig. 2: Cinética de voltaje $(\mathrm{mV})$ vs tiempo $(\mathrm{h})$ de las muestras de mazorca de 0.30, 0.60 y $1.20 \mathrm{~g}$, categorizado en los tres periodos de evaluación.

En la celda con mazorca $0.60 \mathrm{~g}$, después de la cuarta hora del tercer período se observaron valores negativos. Esta inversión en el voltaje pudo ser causado por una falta en la fuente de alimentación de los microorganismos o una carencia en el poder de generación debido a la ausencia de actividad microbiológica en la celda, tal como fue descrito por Oh y Logan (2007), el cual reportó valores negativos de hasta $-600 \mathrm{mV}$, aproximadamente dentro de las primeras 30 horas donde agregaron acetato $1 \mathrm{M}$, dichos resultados fueron similares a lo encontrado en nuestro estudio. Estudios previos muestran que la inversión de voltaje afecta de manera adversa a las bacterias presentes en la biopelícula mostrando una reducción en su rendimiento. Cabe la posibilidad de que la actividad microbiana no se haya presentado estable debido a la presencia de oxígeno en el ánodo, promoviendo la degradación aeróbica y por consiguiente una disminución de materia orgánica como fuente de alimentación de los microorganismos (Lu et al., 2009), dando como resultado valores inestables de voltaje en dicha muestra, y, por consiguiente, el valor máximo de la misma, su densidad de potencia y eficiencia coulombica se afectaron negativamente. El primer período fue considerado como un período de aclimatación en el cual las celdas fueron colonizadas por los microorganismos. Sin embargo, la celda con la dilución de mazorca $0.30 \mathrm{~g}$ fue la que presentó un crecimiento en el voltaje notablemente estable respecto a las demás muestras, lo cual se extendió a lo largo del segundo y tercer período.

Como se muestra en la Figura 3, respecto a los valores máximos de voltaje que se registraron en los diferentes períodos, se observó que el valor más alto se presentó en el tercer período en la dilución de mazorca $1.20 \mathrm{~g}$ $(726 \pm 5.60 \mathrm{mV}$ ), con una diferencia de $191 \mathrm{mV}$ respecto a la dilución de mazorca $0.30 \mathrm{~g}$. La muestra que presentó menores valores máximos durante los tres períodos fue la dilución de mazorca $0.60 \mathrm{~g}$, presentando en el tercer período valores similares al control negativo. Por otro lado, la dilución de mazorca $1.20 \mathrm{~g}$, presentó 
un crecimiento ascendente en sus valores máximos durante todo el experimento, en comparación con las muestras cuyos valores disminuyeron en el tercer período. Buitrón y Pérez (2011) reportaron valores máximos de 540, 530 y $760 \mathrm{mV}$ para sus muestras de 40,80 y $120 \mathrm{~mL}$ (utilizando agua residual y acetato de sodio) dentro de las primeras 24,25 y 143 horas, respectivamente. Los dos primeros valores fueron similares a nuestros resultados del segundo período, en las diluciones de mazorca 0.30 y $0.60 \mathrm{~g}$, ya que dentro de las primeras 20 horas de este período, se presentó valores de 585 y $504 \mathrm{mV}$, respectivamente. En el caso de Logroño et al. (2015), se observaron valores máximos entre 405 y $545 \mathrm{mV}$ en una muestra de $4 \mathrm{~L}$ de suelo amazónico y materia orgánica, lo cual fue inferior a los valores máximos de voltaje de las muestras de mazorca de cacao evaluadas en nuestro estudio.

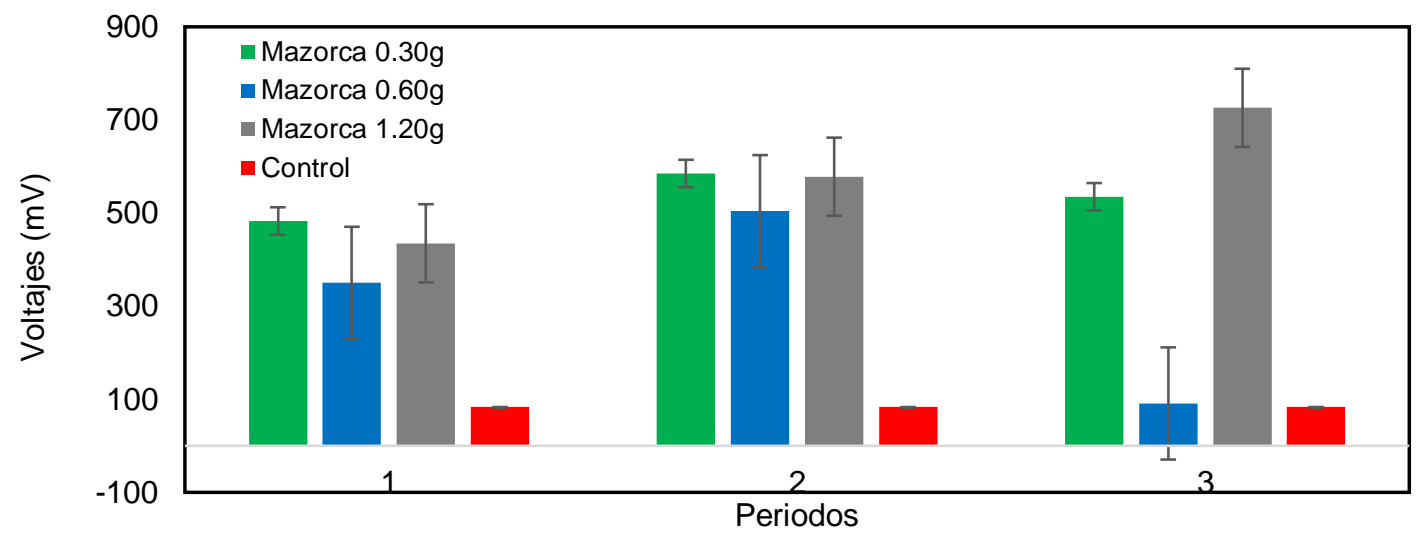

Fig. 3: Voltajes máximos $(\mathrm{mV})$ de las muestras de mazorca de $0.30,0.60$ y $1.20 \mathrm{~g}$, categorizado en los tres periodos de evaluación.

Al evaluarse la densidad de potencia (Figura 4), en la dilución de mazorca $1.20 \mathrm{~g}$, se observó un incremento exponencial en comparación a los demás tratamientos, registrándose una densidad máxima de potencia de $11.75 \mathrm{~mW} / \mathrm{m}^{2}$ con $692 \mathrm{mV}$. En la dilución de mazorca 0.30 y $0.60 \mathrm{~g}$, la densidad máxima de potencia se registró en el segundo período, presentándose valores de 4.14 y $3.59 \mathrm{~mW} / \mathrm{m}^{2}$, respectivamente.

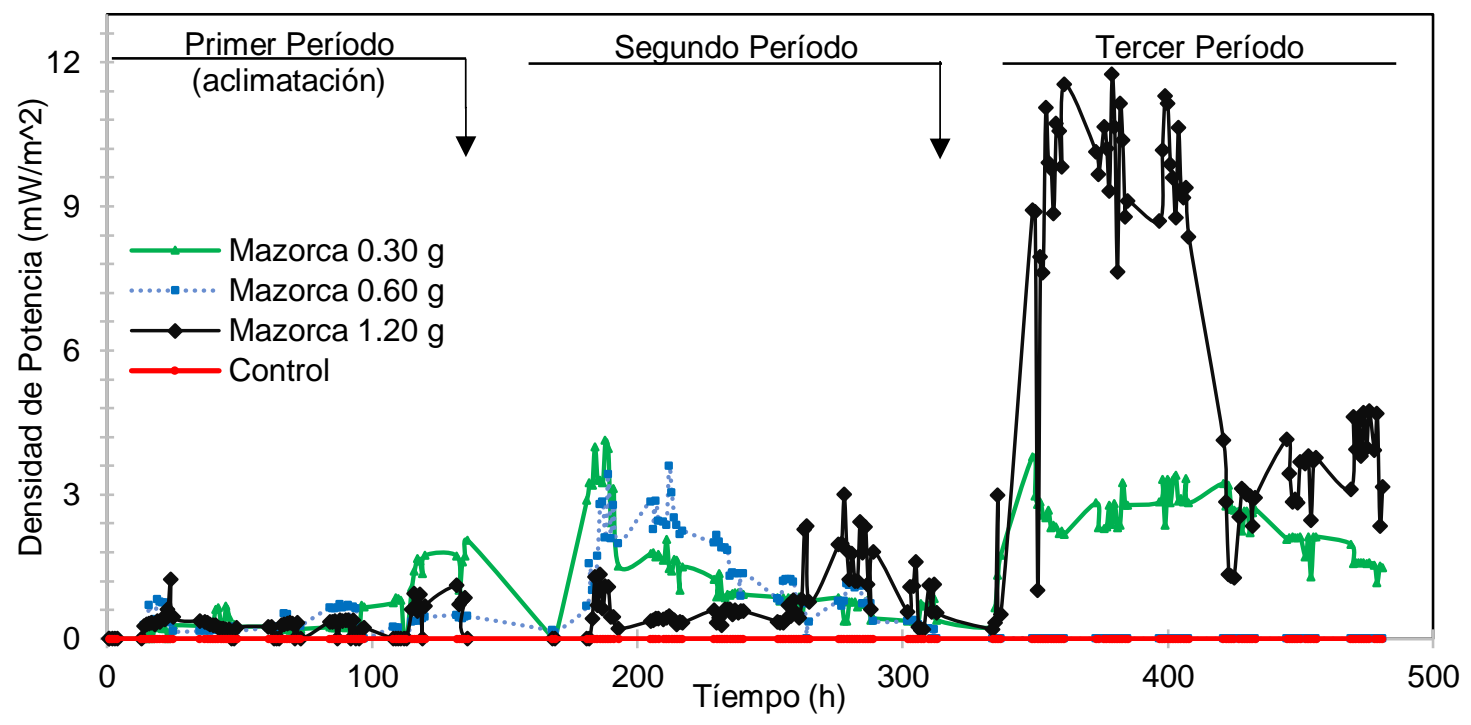

Fig. 4: Distribución de la densidad de potencia ( $\mathrm{mW} / \mathrm{m} 2)$ vs tiempo $(\mathrm{h})$ de las muestras de mazorca de 0.30, 0.60 y $1.20 \mathrm{~g}$, categorizado en los tres periodos de evaluación.

La densidad de potencia reportada con respecto al área del ánodo, aproximadamente comprende un rango de $4.85 \mathrm{~mW} / \mathrm{m}^{2}$ (Mora y Bravo, 2017) a $392 \mathrm{~mW} / \mathrm{m}^{2}$ (Buitrón y Pérez, 2011) utilizando como sustrato agua residual doméstica, y entre 16 a $28 \mathrm{~mW} / \mathrm{m}^{2}$, utilizándose sedimentos anaerobios (Cervantes, 2011). Dichos resultados son similares a nuestro estudio, cuyo valor máximo de densidad de potencia fue de $11.75 \mathrm{~mW} / \mathrm{m}^{2}$, correspondiente a la dilución de mazorca $1.20 \mathrm{~g}$. En general, se observó que los resultados con valores más altos de densidad de potencia fueron los correspondientes a la muestra con mayor concentración de sustrato. En la Tabla 1, se observa que al evaluarse la densidad de potencia respecto al volumen de la cámara anódica, se encontró similitud con los datos anteriores, siendo la diluciones de mazorca 1.20 y $0.30 \mathrm{~g}$ las que presentaron los niveles más altos, 0.28 y $0.10 \mathrm{~W} / \mathrm{m}^{3}$, respectivamente. Dichos valores fueron inferiores a la 
densidad de potencia de $4.50 \mathrm{~W} / \mathrm{m}^{3}$, reportada por Buitrón y Pérez (2011). Por otro lado, la eficiencia coulombica (Tabla 1) registrada en el presente estudio para las diluciones de mazorca fue menor al $1 \%$, presentando los valores más altos, las muestras de mazorca 1.20 y $0.30 \mathrm{~g}$ (0.33 y $0.08 \%$, respectivamente).

Tabla 1: Parámetros de desempeño de las muestras de mazorca de 0.30, 0.60 y $1.20 \mathrm{~g}$.

\begin{tabular}{|l|c|c|c|}
\hline \multirow{2}{*}{ Tratamiento } & \multicolumn{2}{|c|}{ Densidad de potencia } & \multirow{2}{*}{$\begin{array}{c}\text { Eficiencia } \\
\text { coulombica (\%) }\end{array}$} \\
\cline { 2 - 3 } & $\mathrm{mW} / \mathrm{m}^{2}$ & $\mathrm{~W} / \mathrm{m}^{3}$ & 0.08 \\
\hline Mazorca $0.30 \mathrm{~g}$ & 4.14 & 0.10 & 0.00 \\
\hline Mazorca $0.60 \mathrm{~g}$ & 3.59 & 0.08 & 0.33 \\
\hline Mazorca $1.20 \mathrm{~g}$ & 11.75 & 0.28 & 0.00 \\
\hline Control & 0.00 & 0.00 & \\
\hline
\end{tabular}

Es importante mencionar, que la eficiencia coulombica fue calculada a partir de datos de glucosa, dando a entender que el sustrato fue mayoritariamente glucosa, sin embargo, la mazorca de cacao posee azúcares reductores como fructosa principalmente y en menor cantidad glucosa (Campos-Vega et al., 2018). Por otro lado, Vogl et al., (2016) encontraron eficiencias coulombicas de $40 \pm 2 \%$ en una celda de operación por lote con sustrato de glucosa y acetato. Cervantes (2011) describe que generalmente la eficiencia coulombica disminuye por el empleo de aceptores alternos de electrones, al igual que Lu et al. (2009), el cual menciona que el efecto de la difusión de oxígeno del cátodo en la celda puede provocar la degradación aeróbica del sustrato, otros factores que pueden influir son también la fermentación y la metanogénesis.

\section{Mucílago}

Como se muestra en la Tabla 5, la curva de voltaje que mostró mayor estabilidad durante los períodos de evaluación correspondió a la dilución de mucílago 12.50\%. Desde las 181 hasta las 260 horas, se observó un lento aumento del voltaje, desde los 341 hasta los $533 \mathrm{mV}$. A partir de las 261 horas, el voltaje decayó lentamente desde los 504 hasta los $431 \mathrm{mV}$ a las 313 horas, tiempo de finalización del segundo período. Durante el tercer período, a las 381 horas, se observó que el voltaje máximo alcanzado fue de $474 \mathrm{mV}$, encontrándose durante gran parte del estudio entre los 400 a $500 \mathrm{mV}$, finalizando a las 481 horas en $407 \mathrm{mV}$. Sin embargo, si bien la dilución de mucílago $12.50 \%$ fue la que se mantuvo más estable, la dilución de mucílago $6.25 \%$ alcanzó un voltaje máximo de $843 \mathrm{mV}$ a las 349 horas durante el tercer período, siendo este el mayor voltaje obtenido durante el estudio. A las 359 horas, decayó hasta los $476 \mathrm{mV}$, para luego ir descendiendo hasta los $308 \mathrm{mV}$ a las 472 horas, finalizando este período con $343 \mathrm{mV}$ a las 481 horas.

Un estudio realizado por Buitrón y Pérez (2011) con una muestra de aguas residuales y una celda de una cámara de $120 \mathrm{~mL}$, reportó un voltaje máximo de $760 \mathrm{mV}$, al utilizarse cámaras de 40, 80 y $120 \mathrm{~mL}$. Otro estudio realizado con aguas residuales de la industria chocolatera, obtuvo un voltaje máximo de $0.40 \mathrm{~V}$ después de las 135 horas en una CCM con puente salino y $0.50 \mathrm{~V}$ después de las 177 horas en otra CCM con membrana de intercambio protónico. Asimismo, el mayor voltaje obtenido con un medio sintético compuesto por glucosa como fuente de carbono, fue de $0.51 \mathrm{~V}$ (Patil et al., 2009). Como se observa, respecto a estudios anteriores, en nuestro estudio se obtuvo valores mayores de voltaje utilizando muestras de mucílago de cacao como sustrato.

Asimismo, en la Fig. 5, se observa que los valores de voltaje de la dilución de mucílago $25 \%$, se mantuvo alrededor de los $100 \mathrm{mV}$ con una variación entre los 99 a $226 \mathrm{mV}$ entre las 108 y 136 horas, durante el primer período. Sin embargo, no se evidenció un incremento de voltaje durante el segundo ni tercer período, alcanzándose un pico máximo de $467 \mathrm{mV}$ a las 428 horas, finalizando en $150 \mathrm{mV}$ a las 481 horas. Al comparar estos resultados con los presentados por Christwardana et al. (2018) se observa que los autores a una concentración de $5 \mathrm{mg} / \mathrm{mL}$, a una relación de glucosa/levadura:1, obtuvieron como valor máximo $0.46 \mathrm{~V}$ y a medida que la relación aumentaba de 5 a 10, el voltaje también se incrementaba $(0.51$ y $0.65 \mathrm{~V}$, respectivamente). Estos resultados fueron similares al presente estudio, en términos de voltaje, más no en términos de concentración debido a que Christwardana et al. (2018) utilizó concentraciones mayores de sustrato.

Kong et al., (2018) reportaron que las concentraciones de glucosa óptimas para el desempeño de una CCM fluctuaron entre $0.50 \mathrm{a} 4 \mathrm{~g} / \mathrm{L}$. Sin embargo, a medida que la concentración del sustrato se incrementó, la CCM disminuyó su desempeño. Dicho estudio muestra voltajes de $0.82 \mathrm{~V}$ para concentraciones de 0.50 y $1 \mathrm{~g} / \mathrm{L}$ de glucosa, muy similar a lo observado en el presente estudio. Se reporta también un voltaje de $0.74 \mathrm{~V}$ a una concentración de $2 \mathrm{~g} / \mathrm{L}$, y si bien el comportamiento de caída de voltaje se cumple en la presente investigación, los valores difieren. Esto puede deberse a los diferentes sustratos, ya que el autor trabajó con glucosa y la presente investigación con diluciones de mucílago, que presentan diferentes compuestos en distintas proporciones: agua (78-80\%), azúcares simples (10-15\%), ácido cítrico (1-3\%), proteínas $(\leq 1 \%)$, grasas $(\leq$ 
$0.50 \%$ ) y aminoácidos ( $\leq 0.20 \%$ ) (Romero y Zambrano, 2012), lo cual a una determinada concentración puede tener un efecto positivo como adverso en la generación de voltaje puesto que a una mayor concentración se promueve la acidificación del medio, mediante la fermentación, lo que puede ocasionar caídas de voltaje (López, 2014) y aumentar la resistencia interna del medio (Kong et al., 2018). Adicionalmente, un lodo típico está mayormente formado por bacterias fermentativas metanogénicas y sulfo reductoras, estas pueden ocupar espacio disponible en el ánodo lo que impediría una generación eficiente de energía y provocar diferentes potenciales (López, 2014).

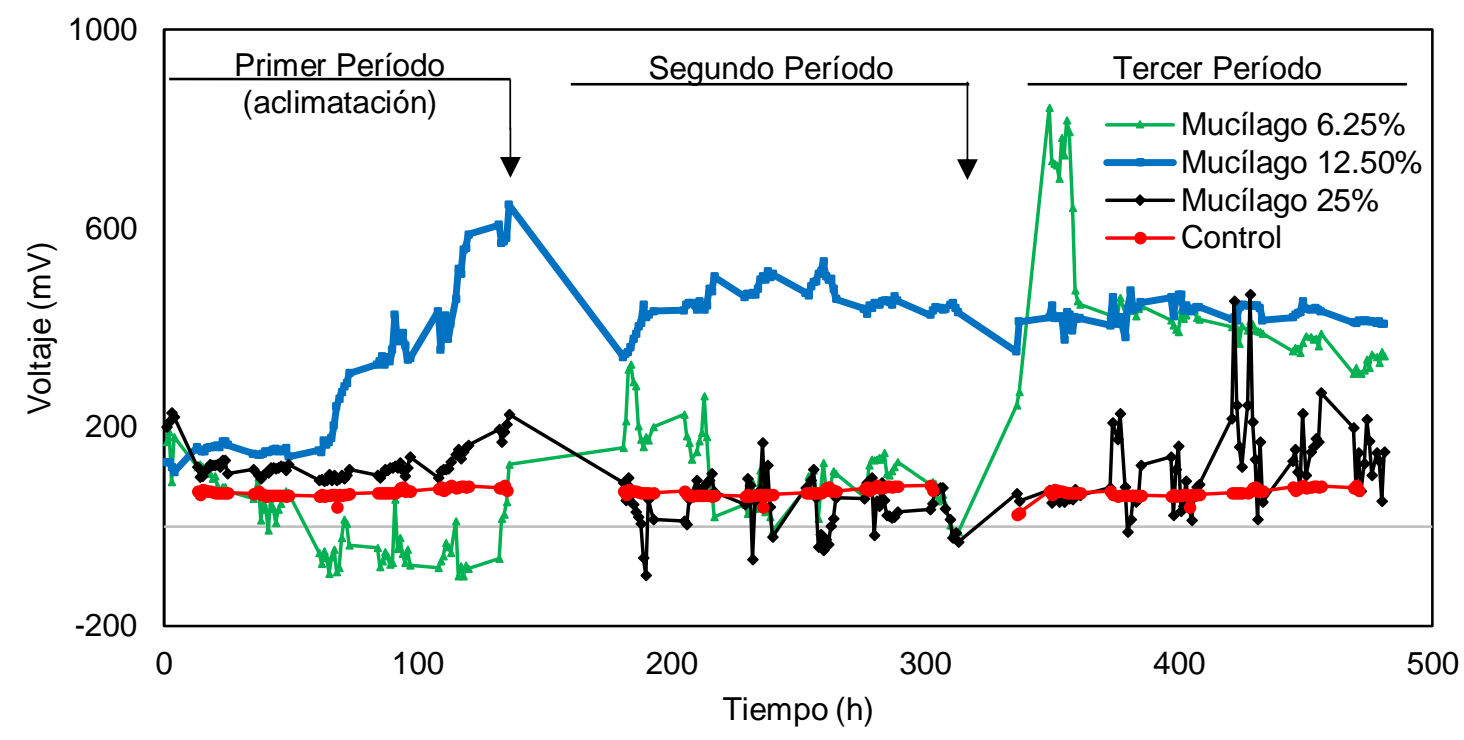

Fig. 5: Cinética de voltaje $(\mathrm{mV})$ vs tiempo $(\mathrm{h})$ de las muestras de mucílago $6.25 \%, 12.50 \%$ y $25 \%$, categorizado en los tres periodos de evaluación

En la Fig. 6, se muestra los máximos voltajes obtenidos en función a la concentración de mucílago durante cada período de reemplazo. Durante el período de aclimatación (primer período), las diluciones de mucílago $12.50 \%$ y $6.25 \%$ mostraron el mayor y menor voltaje ( 647 y $190 \mathrm{mV}$, respectivamente). Durante el segundo período, el mayor voltaje (533 mV), fue presentado por la dilución de mucílago 12.50\% pero disminuyó en un $21 \%$ respecto al período de aclimatación. Finalmente, durante el tercer período, se observó que el mayor voltaje fue alcanzado por la dilución de mucílago $6.25 \%(843 \mathrm{mV})$ con un incremento del $61 \%$ respecto al segundo período, seguido por mucílago $12.50 \%$ (474 mV) con una disminución del $12 \%$ y mucílago $25 \%$ (467 $\mathrm{mV}$ ) con un incremento del $63.80 \%$. Asimismo, se evaluó la densidad de potencia en función al área del ánodo y al volumen del sustrato en $\mathrm{mW} / \mathrm{m}^{2}$ y W/m $/ \mathrm{m}^{3}$, respectivamente. Como se muestra en la Figura 7 , la muestra que mantiene una densidad de potencia por área del ánodo durante los tres diferentes períodos fue la dilución de mucílago $12.50 \%$. En el caso de mucílago $6.25 \%$, en el tercer período alcanzó su valor máximo de 5.94 $\mathrm{mW} / \mathrm{m}^{2}$ y $0.14 \mathrm{~W} / \mathrm{m}^{3}$.

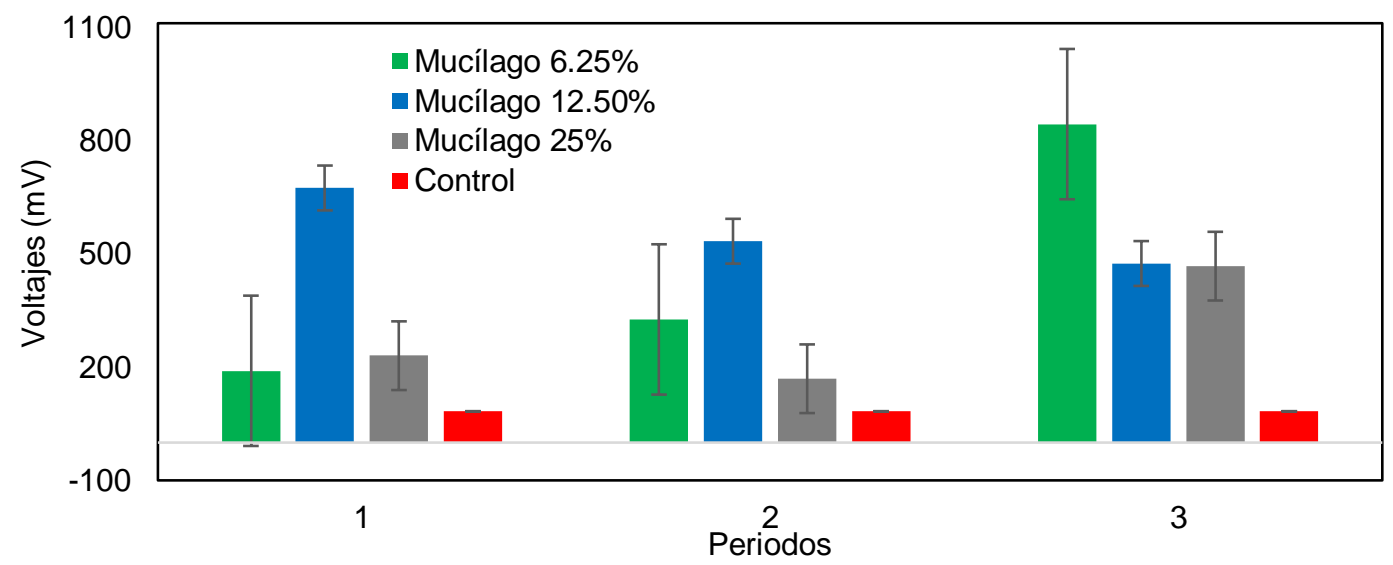

Fig. 6: Voltajes máximos $(\mathrm{mV})$ de las muestras de mucílago $6.25 \%, 12.50 \%$ y $25 \%$, categorizado en los tres periodos de evaluación 


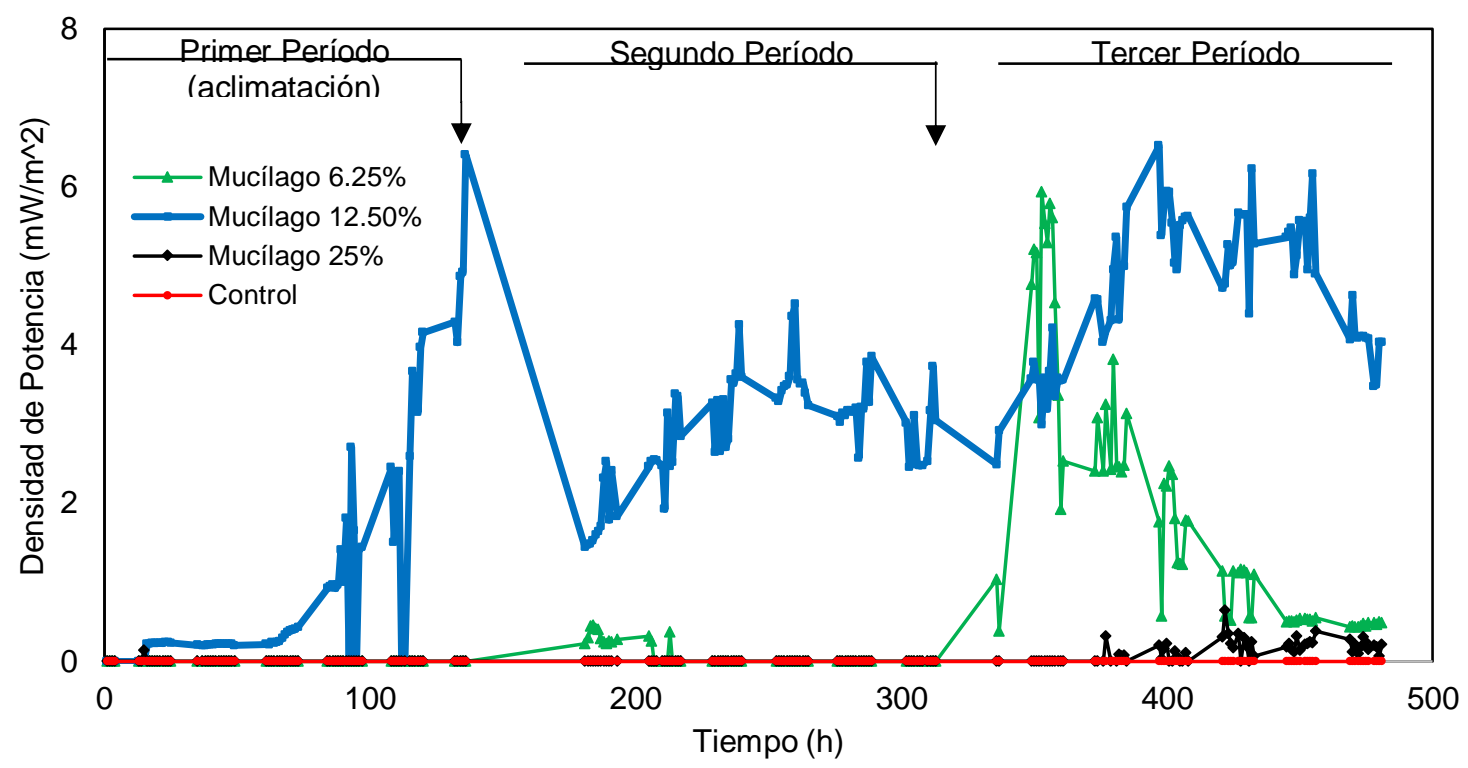

Fig. 7: Distribución de la densidad de potencia $(\mathrm{mW} / \mathrm{m} 2)$ vs tiempo $(\mathrm{h})$ de las muestras de mucílago 6.25\%, $12.50 \%$ y $25 \%$, categorizado en los tres periodos de evaluación

La dilución de mucílago $25 \%$, fue la que obtuvo la menor producción con un máximo de $0.64 \mathrm{~mW} / \mathrm{m}^{2}$ y 0.02 $\mathrm{W} / \mathrm{m}^{3}$ (Tabla 2). La mayor densidad de potencia reportada hasta el momento es de $5.61 \mathrm{~W} / \mathrm{m}^{2}$ utilizando un ánodo macroporoso de grafeno multicapa 3D en sustrato de acetato (Ren et al., 2016). Sin embargo, Chaturvedi y Verma (2016) realizaron una comparación de la densidad de potencia por área de ánodo generada por diferentes sustratos, reportándose que este parámetro se encuentra en el rango de 1 a 3600 $\mathrm{mW} / \mathrm{m}^{2}$, con la mayor cantidad de valores fluctuando entre los 10 a $1000 \mathrm{~mW} / \mathrm{m}^{2}$. Hao et al. (2016) muestra resultados de densidad de potencia de $555 \mathrm{~mW} / \mathrm{m}^{2}$ en tres celdas de combustible microbiano con un total de $125 \mathrm{~mL}(5 \mathrm{~cm} \times 5 \mathrm{~cm} \times 5 \mathrm{~cm})$, utilizando como sustrato glucosa. Estos resultados muestran que la experimentación realizada se encuentra por debajo del rango normal de densidad de potencia, demostrando así que, si bien existe liberación de electrones no hay una transferencia de éstos al cátodo. Lo mencionado anteriormente se corrobora con las eficiencias coulómbicas de cada muestra de mucílago de nuestro estudio, $0.01 \%$ (mucílago $6.25 \%$ ), $0.006 \%$ (mucílago $12.50 \%$ ) y $0.00 \%$ (mucílago $25 \%$ ), que resultaron ser bajas al compararlas con otros sustratos.

Tabla 2: Parámetros de desempeño de las muestras de mucílago 6.25\%, $12.50 \%$ y 25\%.

\begin{tabular}{|l|c|c|c|}
\hline \multirow{2}{*}{ Tratamiento } & \multicolumn{2}{|c|}{ Densidad de potencia } & $\begin{array}{c}\text { Eficiencia coulombica } \\
(\%)\end{array}$ \\
\cline { 2 - 4 } & $\mathrm{mW} / \mathrm{m}^{2}$ & $\mathrm{~W} / \mathrm{m}^{3}$ & 0.01 \\
\hline Mucílago $6.25 \%$ & 5.94 & 0.14 & 0.01 \\
\hline Mucílago $12.50 \%$ & 6.52 & 0.15 & 0.00 \\
\hline Mucílago $25 \%$ & 0.64 & 0.02 & 0.00 \\
\hline Control & 0.00 & 0.00 & \\
\hline
\end{tabular}

\section{CONCLUSIONES}

De acuerdo a los resultados obtenidos se puede concluir que las muestras de mazorca $1.20 \mathrm{~g}$ y mucílago $12.50 \%$ presentaron los mayores desempeños eléctricos frente a las diluciones evaluadas. Sin embargo, la dilución de mazorca $1.20 \mathrm{~g}$ no resultó tan estable como la muestra de mazorca $0.30 \mathrm{~g}$. Asimismo, la muestra de mucílago $12.50 \%$ no alcanzó un desempeño comparable con la literatura estudiada. El máximo potencial eléctrico obtenido de los residuos de cacao (mazorca $1.20 \mathrm{~g}$ y mucílago $12.5 \%$ ) durante el presente estudio fue de $0.01 \mathrm{~mW}$. Finalmente, se recomienda realizar mayores estudios con la muestra de mucílago y concentraciones superiores de mazorca, incluyendo aumento de tamaño de la celda, variación de electrodos, disminución de resistencia externa y configuración de circuito alterno.

\section{AGRADECIMIENTOS}

Este estudio fue financiado por el Fondo Nacional de Desarrollo Científico, Tecnológico y de Innovación Tecnológica (FONDECYT) del Consejo Nacional de Ciencia, Tecnología e Innovación Tecnológica (CONCYTEC) del Perú y la Universidad Científica del Sur, Contrato 137-2017-FONDECYT. Se agradece al Laboratorio de Química y Bioquímica de Productos Naturales de la Universidad Científica del Sur por facilitar sus instalaciones para la ejecución de la fase experimental de esta investigación. 


\section{NOTACIÓN}

$\mathrm{A}=$ Área del electrodo anódico (m2)

$\mathrm{b}=\mathrm{N}^{\circ}$ de moles de electrones producidos por una mol de sustrato $(\mathrm{b}=24)$

$\mathrm{F}=$ cte de Faraday $(98485 \mathrm{C} / \mathrm{mol}$ de e-)

$\mathrm{I}=$ Intensidad de corriente $(\mathrm{mA})$

$\mathrm{I}=$ Intensidad de corriente $(\mathrm{mA})$

$\mathrm{M}_{\mathrm{i}}=$ peso molecular del sustrato $(180 \mathrm{~g} / \mathrm{mol})$

$\mathrm{P}_{\mathrm{A}}=$ Densidad de potencia por unidad de área del electrodo anódico $(\mathrm{mW} / \mathrm{m} 2)$

$\mathrm{PV}=$ Densidad de potencia por unidad de volumen del sustrato $(\mathrm{mW} / \mathrm{m} 3)$

$\mathrm{S}_{\mathrm{i}}=$ concentración del sustrato $(\mathrm{g} / \mathrm{L})$

$\mathrm{U}=$ Voltaje $(\mathrm{mV})$

$\mathrm{U}=$ Voltaje $(\mathrm{mV})$

$\mathrm{v}=$ volumen $(\mathrm{L})$

$\mathrm{V}=$ Volumen del sustrato $(\mathrm{m} 3)$

\section{REFERENCIAS}

Arteaga, Y., Estudio del Desperdicio del Mucilago de cacao en el Cantón Naranjal (provincia del Guayas), Revista ECA Sinergia, 4(1), 49-59 (2013).

Botero, N., Londoño L.V., y Rojas L.F., Extracción de Polifenoles Totales Asistida por Enzimas, a partir de Residuos de la Industria del Cacao, doi: 10.15446/agron.colomb.sup.2016n1.58784, Agronomía Colombiana, 1, S622-S625 (2016).

Buitrón, G., y Pérez, J., Producción de Electricidad en Celdas de Combustible Microbianas Utilizando Agua Residual: Efecto de la Distancia entre Electrodos, TIP Revista Especializada En Ciencias Químico-Biológicas, 14(1), 5-11 (2011).

Campos-Vega, R., Nieto-Figueroa K.N., y Oomah B.D., Cocoa (Theobroma cacao L.) pod husk: Renewable Source of Bioactive Compounds, doi: doi.org/10.1016/j.tifs.2018.09.022, Trends in Food Science \&Technology, 81, 172-184 (2018)

Cervantes, C., Biodegradación de Aguas Residuales y Producción de Electricidad en una Celda de Combustible Microbiano, Universidad Nacional Autónoma de México, México (2011).

Chaturvedi, V., y Verma, P., Microbial Fuel Cell: a Green Approach for the Utilization of Waste for the Generation of Bioelectricity, doi: doi.org/10.1186/s40643-016-0116-6, Bioresources and Bioprocessing, 3(38), 1-14 (2016).

Chouler, J., Padgett, G.A., y otros 5 autores, Towards Effective Small Scale Microbial Fuel Cells for Energy Generation from Urine, doi: doi.org/10.1016/j.electacta.2016.01.112, Electrochimica ACTA, 192, 89-98 (2016).

Christwardana, M., Frattini, D., y otros 3 autores, Optimization of glucose concentration and Glucose/Yeast Ratio In Yeast Microbial Fuel Cell Using Response Surface Methodology Approach, doi: doi.org/10.1016/j.jpowsour.2018.09.068, Journal of Power Sources, 402, 402-412 (2018).

Jiménez-Escamilla, M.G., Garibay-Orijel, C., y Borja-Salin, M.A., Modelo Bioquímicamente Estructurado para la Estimación de la Eficiencia de una Celda de Combustible Microbiana, doi: doi.org/10.20937/rica.2018.34.02.13, Revista Internacional de Contaminación Ambiental, 34(2), 331-345 (2018).

Kong, X., Yang, G. y Sun, Y., Performance Investigation of Batch Mode Microbial Fuel Cells Fed With High Concentration of Glucose, doi: 10.26717/BJSTR.2018.03.000864, Biomed J Sci \& Tech Res, 3(2), 3099-3104 (2018).

Liting, H., Zhang, B., y otros 2 autores, Effects of Various Organic Carbon Sources on Simultaneous V(V) Reduction and Bioelectricity Generation in Single Chamber Microbial, doi: doi.org/10.1016/j.biortech.2015.11.060, Bioresource Technology, 201, 105-110 (2016).

Liu, H., y Logan, B. E., Electricity Generation Using an Air-Cathode Single Chamber Microbial Fuel Cell in the Presence and Absence of a Proton Exchange Membrane, doi: doi.org/10.1021/es0499344, Environ. Sci. y Technol., 38(14), 40404046 (2004).

Logroño, W., Echevarría, M., Recalde, C. y Graziani, P., Bioconversión de Residuos Sólidos Orgánicos con Suelos de la región Amazónica y Alto Andina del Ecuador en Celdas de Combustible Microbiano de Cámara Simple, doi:dx.doi.org/10.4067/S0718-07642015000200008, Información tecnológica, 26(2), 61-68 (2015).

López, J.D., Desarrollo de una Celda De Combustible Microbiana (CCM) para Aplicación en Tratamiento de Aguas Residuales, Repositorio institucional Centro de investigación y desarrollo tecnológico en electroquímica, México (2014).

Lu, N, Zhou, S. y otros 3 autores, Electricity generation from Starch Processing Waste Water Using Microbial Fuel Cell Technology, doi: doi:org//10.1016/j.bej.2008.10.005, Biochemical Engineering Journal, 43(3), 246-251 (2009).

Martinez, C.M., Zhu, X., y Logan, B.E., AQDS Immobilized Solid-Phase Redox Mediators and their Role during Bioelectricity Generation and RR2 Decolorization in Aircathode Single-Chamber Microbial Fuel Cells, doi: doi.org/10.1016/j.bioelechem.2017.07.007, Bioelectrochemistry, 118, 123-130 (2017). 
Ministerio de Agricultura, Serie de Estadísticas de Producción Agrícola (SEPA), Dirección de Estadística Agraria de la Dirección General de Seguimiento y Evaluación de Políticas, Lima, Perú (2020).

Mora, A. y Bravo, E., Diversidad Bacteriana Asociada a Biopelículas Anódicas en Celdas de Combustible Microbianas Alimentadas con Aguas Residuales, doi: 10.15446/abc.v22n1.55766, Acta Biológica Colombiana, 22(1), 77-84 (2017).

Morales, O., Borda, A. y otros 4 autores, La alianza Cacao Perú y la Cadena Productiva del cacao Fino de Aroma, $1^{a}$ ed., 12, Universidad ESAN, Lima, Perú (2015).

Oh, S.E., y Logan, B.E., Voltage Reversal during Microbial Fuel Cell stack operation, doi: doi.org/10.1016/j.jpowsour.2007.02.016, Journal of Power Sources, 167 (1), 11-17 (2007).

Patil, S.A., Prasad, V., y otros 5 autores, Electricity Generation Using Chocolate Industry Wastewater and its Treatment in Activated Sludge Based Microbial Fuel Cell and Analysis of Developed Microbial Community in the Anode Chamber, doi:doi.org/10.1016/j.biortech.2009.05.041, Bioresource Technology, 100 (21), 5132-5139 (2009).

Ren, H., Tian, H., y otros 3 autores, A Miniaturized Microbial Fuel Cell with Three-Dimensional Graphene Macroporous Scaffold Anode Demonstrating a Record Power Density of Over 10,000 Wm³, doi: 10.1039/C5NR07267K, Nanoscale, 8(6), (2016).

Romero, C. y Zambrano, A., Análisis de Azúcares en Pulpa de Cacao por Colorimetría y Electroforesis Capilar, Revista Científica UDO Agrícola, 12(4), 906-913 (2012).

Romero, C., Estudio del Cacao en el Perú y el Mundo, Situación Actual y Perspectivas en el Mercado Nacional e Internacional al 2015, $1^{\text {a }}$ Ed, 30, Ministerio de Agricultura y Riego, Lima, Perú (2016).

Slate, A.J., Whitehead, K.A., y otros 2 autores, Microbial Fuel Cells: An Overview of Current Technology, doi: doi.org/10.1016/j.rser.2018.09.044, Renewable and Sustainable Energy Reviews, 101, 60-81 (2019).

APHA, AWWA, y WEF, Method 52220 D, Chemical Oxygen Demand. Standard Methods for the Examination Water and Wastewater (2017).

Trade Map, Trade statistics for international business development, International Trade Centre, www.trademap.org.

Velarde, M.L., Rodríguez, F.J., y otros 4 autores, Performance of a Microbial Fuel Cell operated with vinasses using different cod concentrations, doi: doi.org/10.20937/RICA.2017.33.03.14, Revista Internacional de Contaminación Ambiental, 33(3), 521-528 (2017).

Vogl, A., Bischof, F., y Wichern, M., Single Chamber Microbial Fuel Cells for High Strength Wastewater and Blackwater Treatment-A comparison of Idealized Wastewater, Synthetic Human Blackwater, and Diluted Pig Manure, doi: dx.doi.org/10.1016/j.bej.2016.08.007, Biochemical Engineering Journal, 115, 64-71 (2016). 